\title{
ADSORPTION ABILITY OF ACTIVATED CARBON OBTAINED FROM SUB-BITUMINOUS COAL (LEBU, CHILE) TO CAPTURE TRIMETHYLAMINE
}

\author{
PAOLA MÉNDEZ ${ }^{1, *}$, CHRISTIAN NUÑEZ ${ }^{1}$, JAIME R. CABRERA-PARDO ${ }^{1}$, CRISTIAN PAZ $^{3}$, \\ JUAN MANUEL BARRAZA ${ }^{4}$, ROSARIO CASTILLO ${ }^{5}$ AND CARLOS PEÑA-FARFAL ${ }^{2, *}$ \\ ${ }^{1}$ Departamento de Química, Facultad de Ciencias, Universidad del Bío-Bío, Av. Collao 1202 Concepción, Chile. \\ ${ }^{2}$ LABEL-POLECTRO, Departamento de Química Analítica e Inorgánica, Facultad de Ciencias Químicas, Universidad de Concepción, \\ Barrio Universitario SN, 4070043, Concepción, Chile. \\ ${ }_{3}^{3}$ Departamento de Ciencias Básicas, Universidad de la Frontera, Francisco Salazar Av. 1145 Temuco, Chile. \\ ${ }^{4}$ Departamento de Ingeniería Química, Facultad de Ingeniería, Universidad del Valle, Cl. 13 \#100-00, Valle del Cauca-Cali, \\ Colombia. \\ ${ }^{5}$ Departamento de Análisis Instrumental, Facultad de Farmacia, Universidad de Concepción, Barrio Universitario SN, 4070043, \\ Concepción, Chile.
}

\begin{abstract}
The removal of organic contaminants, especially trimethylamine (TMA), have been successfully achieved using carbon activate. In this article, we report the formation of carbon activate (CA-SM) isolated from sub-bituminous coal in small mantles (SM) at the Mine "Mantos Negros" (Lebu, Chile). This coal was subjected to thermal oxidation with $\mathrm{CO} 2$ at $950^{\circ} \mathrm{C}$ and their TMA adsorption capacity evaluated. SM and CA-SM were physically and chemically characterized showing that the activated carbon increased the surface porosity as well as the Iodine Index from $2.5 \mathrm{mg} \mathrm{I} / \mathrm{g}$ to $434 \mathrm{mg} \mathrm{I} / \mathrm{g}$ coal. The proximal and elementary analyses of CASM showed a significant reduction of sulfur, nitrogen and hydrogen, and increased composition of carbon and oxygen. These results together with FTIR and Boehm titration suggest that the surface composition of the activated carbon is acidic in nature. The adsorption of TMA by CA-SM was evaluated in dissolution at different $\mathrm{pH}$ and exposure time conditions. We found that TMA can be fully absorbed (50 ml TMA at $4 \mathrm{mg} / \mathrm{L}$ and $0.2000 \mathrm{~g}$ of CA-SM) under neutral and basic $\mathrm{pH}$ after 60 minutes of exposure.

The feasibility of producing activated carbon from sub-bituminous coal from Province of Arauco, Chile, is a promising alternative to develop coal-based products displaying adsorbent properties useful to control amine-derived contaminants produced in the fishing industry.
\end{abstract}

Keywords: Activated carbon, trimethylamine, adsorption process, physical and chemical characterization.

\section{INTRODUCTION}

In Chile, coal mining was the first economic source for the development of the Center South of the country, mainly in Provinces of Concepción, Arauco, Valdivia and Magallanes. While the coal mining is almost extinguished nowadays, coal reserves in these areas are estimated to last over 100 years. For instance, in Arauco region, there are a series of important deposits of bituminous and sub-bituminous in Eocene strata, with an approximated production of five metric tons per year ${ }^{1}$. Thus, one of our main research programs is taking advantage of this readily accessible carbon-based materials in order to develop products with broad application in industry.

Activated carbon refers to a type of material that corresponds to a form of carbon displaying pores. These pores increase the surface area promoting chemical reactions and adsorption processes, making activated carbon substrates a rather attractive alternative to develop products with interesting applications. The adsorption ability of activated carbon depends on both its texture and chemical properties. Coals are in principle hydrophobic nature, however, this can be tuned by adding polar functional groups on the surface employing oxidizing agents. Oxygen containing groups interact with water, which in turn can absorb other molecules capable of undergoing hydrogen bonds. Thus, the introduction of oxygen containing anchors increases the wettability and consequently the hydrophilicity of coals. This modifies the absorption properties of coals to organic compounds in water, which could be beneficial ${ }^{2}$.

Activated carbon adsorption is a widely used method to remove organic and inorganic pollutants present in wastewaters. Activated carbon materials show a porous pseudo-graphite structure assembled from irregularly arranged polyaromatic layers. The textural features together with the surface chemistry of activated carbon determine their absorption capabilities. Likewise, the pollutant removal efficiency is affected by several parameters including operating conditions and physicochemical properties of wastewater, specifically $\mathrm{pH} .{ }^{3,4}$

TMA is a small and volatile nitrogen-containing organic molecule produced during the decomposition of proteins in the fishing industry. Its uses are broad, among which includes: warning agent for natural gas, ingredient of synthetic flavoring (fish), synthesis of photographic chemical compounds, flotation agents, colorants, pesticides, ion exchange resins, cationic starches and intense sweeteners 5 .
In our efforts to develop carbon-based products using coal form the Province of Arauco, Chile, we prepared activated carbon from this natural source and studied its capability to adsorb TMA. In order to achieve this, we employed gas 5,6 and liquid chromatography with derivatization in precolumn ${ }^{7,8}$. In this report, the derivatization of TMA with 9-fluorenylmethyl cholorormate (FMOC) was used quantify TMA. Our results showed that the activated carbon prepared using coal from Arauco, Chile, displayed the ability to efficiently absorb TMA under mild conditions.

\section{EXPERIMENTAL}

\subsection{Chemicals and reagents}

Coal used to prepare activated carbon was extracted from the small mantle (SM) of the mine "Mantos Negros" placed in Lebu, Region of Biobío Region, Chile, with a diameter of less than $100 \mu \mathrm{m}$. Standard of activated carbon (CAC) was purchased from Merck, Germany.

For the derivatization of trimethylamine the following reagents were used: trimethylamine solution 25\% weight in water (Sigma Aldrich, CAS Number 7550-3), 9-fluorenylmethyl chloroformate for derivatization by HPLC $\geq 99 \%$ (Sigma, Aldrich, CAS 28920-43-6), boric acid p.a $\geq 99.5 \%$ (Sigma, Aldrich), sodium hydroxide, p.a. $\geq 98 \%$ (Sigma, Aldrich), and potassium hydroxide p.a. 90\% (Sigma, Aldrich). As mobile phase, LiChrosolv® acetonitrile HPLC grade (Merck) and $0.5 \mathrm{~mol} / \mathrm{L}$ sodium acetate buffer $\mathrm{pH} 4.2$ (sodium acetate $\mathrm{p} . \mathrm{a} \geq 99 \%$, Sigma, Aldrich) adjusted with acetic acid p.a $\geq 99.7 \%$, (Sigma, Aldrich). All solutions were prepared with miliQ water and were filtered with $0.45 \mu \mathrm{m}$ membrane filters.

\subsection{Instrumentation}

Activated carbon was prepared in a thermolyne horizontal oven with temperature-controlled using a K-type thermocouple and gas controlled atmosphere. Elementary analysis was conducted in a Leco model CHN2000 equipment (Leco Corp, St. Joseph, MI, USA). The proximal analysis was carried out in a LEGO TGA 60 Thermogravimetric Analyzer (SHIMADZU, Kyoto, Japan). FTIR analysis was performed in an equipment Perkin Elmer Spectrum BX FT-IR System (Waltham, MA, USA). The morphological characterization was determinate in a JEOL Scanning Electron JSM-6380 V scanning electronic microscope (JEOL, Ltd, Tokyo, Japan). 
Chromatographic determination was performed in a Merck Hitachi HPLC system equipped with autosampler and fluorescence detector (Merck KG, Darmstadt, Germany). A $\mathrm{C}_{18}$ analytical column was used (Supelco, 250 x 4.6 $\mathrm{mm}, 5 \mu \mathrm{m})$ with precolumn in line $(25 \times 4.6 \mathrm{~mm}, 5 \mu \mathrm{m})$. Data analysis was performed using an interactive graphic software version 6.20 of Varian Inc. (Palo Alto, Ca, USA).

\subsection{Preparation of activated carbon}

The activated carbon was obtained by physical activation following the procedure described by Teng $\mathrm{H}$. et $\mathrm{al}^{9}$ with few modifications. Briefly, 5 grams of sub-bituminous coal (SM) was pre-oxidized in oven using air convection at $185^{\circ} \mathrm{C}$ for 48 hours. Then, the coal was heated at $750{ }^{\circ} \mathrm{C}$ for 60 minutes under $\mathrm{N}_{2}$ atmosphere $\left(\mathrm{N}_{2} 99.99 \%\right.$ purity) using a Thermolyne horizontal oven with heating rate of $10^{\circ} \mathrm{C} / \mathrm{min}$. The system was equipped with an oxygen trap, in order to minimize the combustion of the precursor material. Then, the sample was placed in a refractory ceramic vessel and it was heated at $950{ }^{\circ} \mathrm{C}$ for 180 minutes in an inert $\mathrm{CO}_{2}$ atmosphere, $99.99 \%$ purity in flow of $100 \mathrm{ml} / \mathrm{min}$.

After the thermal process was completed, the activated carbon (CA-SM) was gradually cooled to $50^{\circ} \mathrm{C}$, and the samples were removed and stored in a desiccator under vacuum. The CA-SM was characterized through proximate and elementary analysis, FTIR, SEM, Boehm titration and Iodine index.

\subsection{Characterization of the activated carbon}

The elementary analysis was conducted according to the ASTM D $5373^{10}$. The proximal analysis includes the determination of moisture content, volatile matter, ash and fixed carbon ${ }^{11}$. FTIR analysis was performed using potassium bromide mixed with the sample in a 1:100 ratio $^{12}$ to identify functional groups and the presence of mineral matter. The morphological surface was characterized using an electronic microscope ${ }^{13}$. The acid-base properties of the activated carbons were studied by determining the acid functional groups of the surface, it was used the acid-base titration proposed by Boehm ${ }^{14}$. The specific surface was determined from the iodine index ${ }^{15}$.

\subsection{FMOC-TMA derivatization and chromatographic conditions}

The derivatization ${ }^{8}$ was performed as follows: $0.30 \mathrm{ml}$ of FMOC-Cl at 1.0 $\mathrm{mmol} / \mathrm{L}$ was homogenized with borate buffer $0.250 \mathrm{~mL}$ of $0.05 \mathrm{~mol} / \mathrm{L}, \mathrm{pH} 9$. Then it was added $1 \mathrm{~mL}$ of sample (TMA $10 \mathrm{mg} / \mathrm{mL}$ ) and placed to react by 24 hours at room temperature in darkness. The reaction was quenched by adding $0.30 \mathrm{~mL}$ of $\mathrm{H}_{3} \mathrm{PO}_{4}(2 \%)$.

The product, TMA-FMOC, was injected into the RP-HPLC-FL system under the chromatographic conditions: phosphate buffer $(0.05 \mathrm{~mol} / \mathrm{L}, \mathrm{pH}=4.2)$ : acetonitrile, 70:30, $1.2 \mathrm{~mL} / \mathrm{min}$., detection $\lambda_{\mathrm{Ex} / \mathrm{Em}}=263 / 313 \mathrm{~nm}$.

\subsection{Effect of exposure time on the adsorption of TMA}

The adsorption capacity of TMA by CA-SM and CAC (active carbon commercially available) was studied by stirring of $0.2000 \pm 0.0001 \mathrm{~g}$ of the activated carbon with $100 \mathrm{~mL}$ of TMA at concentration of $4 \mathrm{mg} / \mathrm{L}$ at room temperature.

At predetermined intervals, aliquots $(1.0 \mathrm{~mL})$ were taken and filtered using a $0.45 \mu \mathrm{m}$ filter. Then, derivation of TMA followed by chromatographic detection (section 2.5) renders the amount of TMA adsorbed $\left(\mathrm{q}_{\mathrm{e}}, \mathrm{mg} / \mathrm{g}\right)$, which was determined using the equation 1.

$$
q_{e}=\frac{\left(C_{o}-C_{e}\right)}{W} \cdot V
$$

$\mathrm{C}_{\mathrm{o}}$ is the initial concentration of TMA $(\mathrm{mg} / \mathrm{L})$. Ce is the remaining concentration of TMA $(\mathrm{mg} / \mathrm{L})$ in the system after treatment. $\mathrm{V}$ is the volume of the solution (L), and W is the dry mass of CA-SM (g).

The percentage of removal was calculated by equation (2):

$$
\% \text { removal }=\frac{C i-C f}{C i} \times 100
$$

$\mathrm{C}_{\mathrm{i}}$ and $\mathrm{C}_{\mathrm{f}}$ are the initial and the final concentration of TMA (mg/L).

\subsection{Effect of $\mathrm{pH}$ on the adsorption of TMA}

The influence of $\mathrm{pH}$ on the adsorption process was studied. For this, TMA solutions were prepared at $4 \mathrm{mg} / \mathrm{L}$, with the following $\mathrm{pH}$ conditions: $2.0,4.0$, 7.0 and 9.0. Then, $50 \mathrm{ml}$ of each solution was stirred at room temperature with $0.2000 \pm 0.0001 \mathrm{~g}$ of CA-SM. The adsorption time was evaluated at 0,30 and 60 minutes. Then, samples were derivatized, filtered and analyzed using RP-HPLCFL to determine the amount of TMA adsorbed using equations (1) and (2).

\section{RESULTS AND DISCUSSION}

\subsection{Synthesis and characterization of CA-SM by Scanning Electronic Microscopy}

$5,00 \mathrm{~g}$ of SM produced 3,55 $\mathrm{g}$ of CA-SM with a $71 \%$ yield. SEM analysis of the activated carbon from small mantle shows an increased porosity (Figure 1A and $1 \mathrm{~B}$ ) compared to the starting mineral coal (Figure 1C and 1D), which shows a smooth texture with irregular morphology of the surface as well as the absence of porosity.

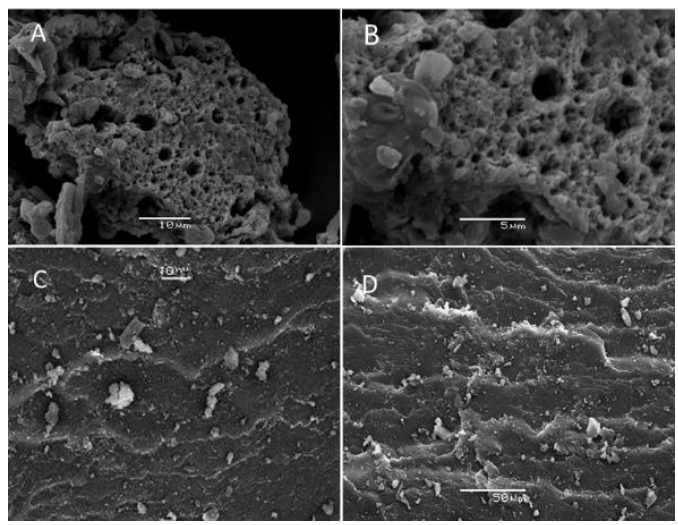

Figure 1. SEM micrographs of A) B) CA-SM, C) D) SM

\subsection{Elementary and proximal analysis}

The proximal and elementary analyses of the starting material SM and the activated carbon CA-SM are summarized in Table 1.

Table 1. Proximate and elemental analysis SM and CA-SM

\begin{tabular}{|c|c|c|c|c|c|c|c|c|c|}
\hline \multicolumn{4}{|c|}{ Proximate analysis } & \multicolumn{4}{|c|}{ Elemental analysis } \\
\hline & Humidity & Ashes & Volatile material & Fixed carbon & C & H & N & O & S \\
\hline SM & 2,93 & 2,19 & 39,77 & 58,04 & 75,37 & 5,32 & 1,96 & 14,22 & 0,95 \\
\hline CA-SM & 1,67 & 0,17 & 50,75 & 48,13 & 80,47 & 2,14 & 0,67 & 16,26 & 0,05 \\
\hline
\end{tabular}

All results are expressed in \% dry base

The proximate analysis showed that activated carbon (CA-SM) has 12.9 folds lower ash content than SM. This is concordant with the higher volatile material of CA-SM; due the greater number of empty spaces in the structure, which activate the surface. Therefore, the carbon bonds that are free when the oxygen is released could react better in the adsorption processes. This can be confirmed by elemental analysis, since an increase in oxygen content is observed. In addition, the content of nitrogen, hydrogen and sulfur decreases when it is subjected to the activation process, being eliminated in the form of gases. In the adsorption studies of liquid substances by activated carbon, the atomic $\mathrm{H} / \mathrm{C}$ and $\mathrm{O} / \mathrm{C}$ ratios of the precursor mineral carbons are factors that control the adsorption properties. The $\mathrm{O} / \mathrm{C}$ atomic ratio is a performance parameter in the coal transformation processes, it has been found that increasing the $\mathrm{O} / \mathrm{C}$ atomic ratio of bituminous coals generates a significant increase in the reactivity in the combustion, because oxygen is very important in the formation of an intermediate structure that facilitates the release of volatile matter during carbonization and activation of the coal. The coal used in the present study has an $\mathrm{O} / \mathrm{C}$ atomic ratio of 0.19 , a high value compared to other carbons that have been studied, meaning that produces more reactive charcoals ${ }^{16}$. 


\subsection{Infrared Spectroscopy of CA-SM and SM}

The FT-IR analysis of samples SM and CA-SM, Figure 2A and 2B respectively, showed that sample SM has more vibration modes than CA-SM, which is reflected with the higher content of oxygen, sulfur and nitrogen.

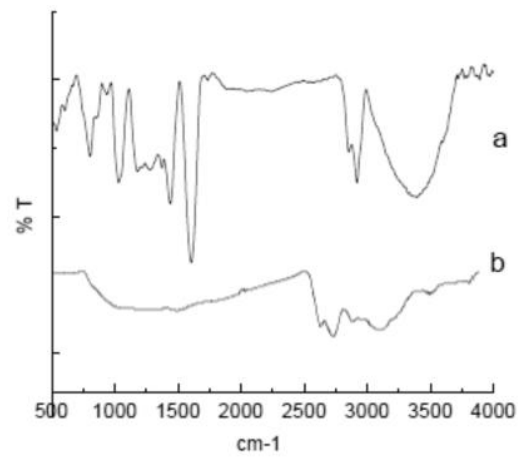

Figure 2. FT-IR spectra for samples of a) SM and b) CA-SM

$\mathrm{SM}$ has a well-defined absorption around $3500 \mathrm{~cm}^{-1}$ which relates with the higher content of humidity than CA-SM. N-H and O-H groups (amines and alcohols), found around $3300 \mathrm{~cm}^{-1}$, are largely present in SM. Vibrations around $1520 \mathrm{~cm}^{-1}$ could be due to $\mathrm{C}=\mathrm{C}$ bonds. Bands between 2850 and $2950 \mathrm{~cm}^{-1}$ are characteristic of the $\mathrm{C}-\mathrm{H}$ bound to $\mathrm{CH}_{2}$ and $\mathrm{CH}_{3}$ groups. This vibration almost disappeared in Figure 2B since CA-SM has a low content of hydrogen $(2.14 \%)$ compared to SM $(5.32 \%)$. In figure $2 \mathrm{~B}$, the band corresponding to stretching vibrations of the $\mathrm{O}-\mathrm{H}$ moves over $3000 \mathrm{~cm}^{-1}$ and this band becomes wider in the oxidized coals such as CA-SM.

\subsection{Iodine index analysis}

The iodine number is an approximate index of the surface area of a porous material, this is due to the fact that iodine is adsorbed efficiently in a monomolecular layer and its size allows it to be housed up to the smallest pores in which the adsorption is carried out. It is expressed in $\mathrm{mg}$ of iodine adsorbed per gram of carbon $\left(\mathrm{mg} \mathrm{I}_{2} / \mathrm{g}\right)$. The iodine value is based on the quantification of iodine adsorbed, evaluating the excess of iodine of a solution with sodium thiosulfate. The Table 2 shows the values of iodine index of SM and CA-SM.

Table 2. Results of iodine index for SM and CA-SM

\begin{tabular}{|c|c|}
\hline Sample & $\mathbf{m g I}_{2} / \mathbf{g}$ \\
\hline SM & $2.5 \pm 0,6$ \\
\hline CA-SM & $434 \pm 13$ \\
\hline
\end{tabular}

CA-SM shows a significant higher value of the iodine index than SM, which indicate an increase of the specific surface in the activated carbon, which is slightly below to those reported in the literature for other activated carbons obtained from coal ${ }^{9}$.

\subsection{Chemical composition by Boehm titration}

The content of acid groups (carboxyl, lactones, phenols and carbonyls) and basic groups were quantified by the titration method proposed by Boehm. For the mineral carbon sample, the results are summarized in the table 3 .

Table 3. Chemical composition for SM and CA-SM by Boehm method

\begin{tabular}{|c|c|c|c|c|c|}
\hline \multirow{2}{*}{ Sample } & \multicolumn{5}{|c|}{ Concentrations of surface groups ( $\boldsymbol{\mu e q} / \mathrm{g})$} \\
\cline { 2 - 6 } & Carboxylic & Lactones & Phenolic & Carbonyls & Basic \\
\hline SM & 0 & 203 & 830 & 1580 & 25 \\
\hline CA-SM & 356 & 343 & 576 & 1974 & 45 \\
\hline
\end{tabular}

After physical activation, SM increased the amount of oxygenated groups, especially the carboxyl groups, giving acidic properties to the obtained CA-SM. The phenolic groups decreased in the CA-SM obtained in comparison to the mineral coal. Basic groups are present in a small proportion, mainly due to the amphoteric nature of coals.
The presence of acid structures (carboxylic and lactones, mainly) would be the main responsible for the adsorption of TMA. These groups interact with cationic molecules, resulting in most of the activated carbon surface to be occupied by TMA (cationic) molecules. On the other hand, the presence of basic structures, which have the preference for anionic species, are responsible for the adsorption of molecules such as water.

\subsection{Effect of contact time on the adsorption of TMA}

In order to evaluate the relation between the exposure time with the absorption of TMA on the activated carbon (mass constant of at $0.2000 \mathrm{~g}$ ), the experiment described in point 2.6 was carried out. The figure 3 shows the percentage TMA adsorbed at different times, for the activated carbon CA-SM and the commercially available carbon ${ }^{18}$ (CAC, Merck).

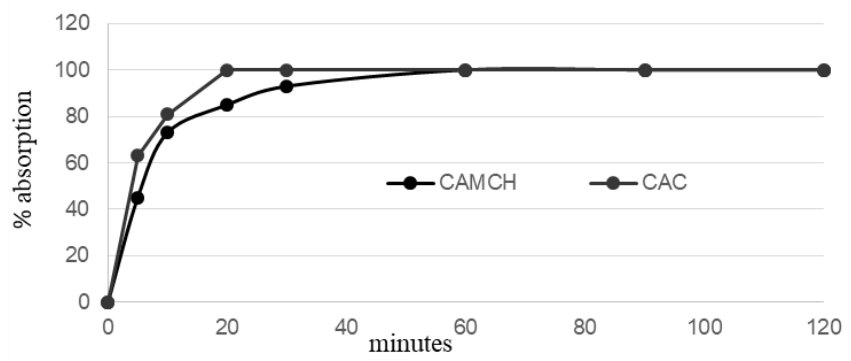

Figure 3. Graphic of the variation of time and its effect on the adsorption of TMA by CA-SM and CAC.

From the figure 3 , it is possible to see that both materials remove $100 \%$ of TMA of the dissolution. The CAC absorbed the $100 \%$ of TMA at 20 minutes while CA-SM has the same result at 60 minutes.

\subsection{Effect of pH on the adsorption of TMA}

The effects of $\mathrm{pH}$ on the adsorption of TMA on activated carbon were studied. The $\mathrm{pH}$ of the solution in which the adsorption phenomena occurs is a very important parameter in for this process, especially in the case of TMA which is a Bronsted base. The magnitude of the electrostatic charges occurring between the functional groups and the adsorbent surface depends mainly of the $\mathrm{pH}$ of the medium.

The percentage of adsorption of TMA at times 0,30 and 60 minutes was measured at $\mathrm{pH} \mathrm{2,4,7}$ and 9, with $0,2000 \mathrm{~g}$ of CA-SM, the results are summarized in Figure 4.

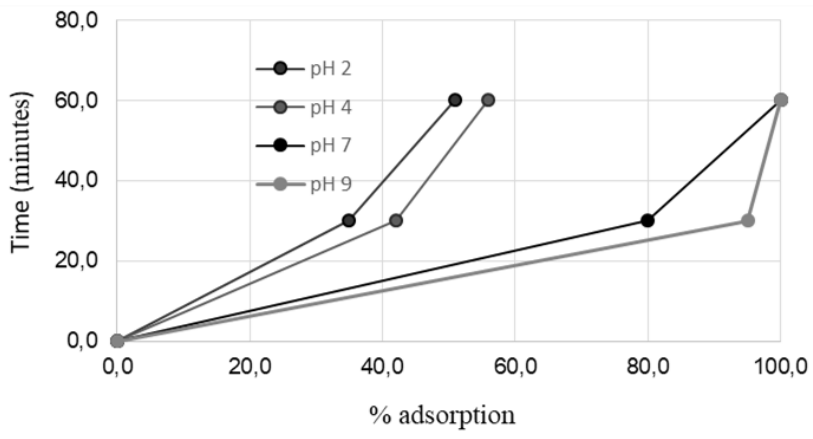

Figure 4. Variation in the TMA adsorption at different $\mathrm{pH}$ and retention time on CA-SM.

Results shown that the absorption capability of CA-SM is highly influenced by the $\mathrm{pH}$. At neutral or basic $\mathrm{pH}$, CA-SM absorbs $100 \%$ of TMA at 60 minutes but, at $\mathrm{pH} 4$ or 2 , the same amount of CA-SM captures only $50 \%$ of TMA. This fact can be explained due the activated carbon surface has an acidic nature which can be deprotonated facilitating the interaction with cationic organic compounds. Therefore, the pair of electrons not shared in the nitrogen atom can be easily donated to the oxygen atoms generated on the activated carbon surface (CA-SM) In turn, changing the $\mathrm{pH}$ of the solution results in the formation of different ionic species and different charges on the carbon surface, decreasing the interaction with the amine in the cationic form. 


\section{CONCLUDING REMARKS}

In conclusion, the present investigation demonstrates that the sub-bituminous coal of the small mantle of the Mine "Mantos Negros" (Lebu, Chile) can be transformed into activated carbon with a specific surface value of $434 \pm 13$ $\mathrm{mgI}_{2} / \mathrm{g}$. This activated carbon showed a great number of oxygenated functional groups in the surface that were formed through pre-oxidation treatments with air and activation with $\mathrm{CO}_{2}$ at $950{ }^{\circ} \mathrm{C}$ for 180 minutes.

The active carbon generated in this study is suitable for removal of TMA, a common contaminant of water and air from the fishing industry, using appropriate exposure times between active carbon and TMA under controlled $\mathrm{pH}$ conditions. The good behavior of the coals in the Adsorption of TMA in aqueous solution is due to their microporous character and the acidic chemical surface activated with $\mathrm{CO}_{2}$ at high temperatures.

It was possible to show the feasibility of producing activated carbon from subbituminous coal from Lebu, Province of Arauco, Chile, thus achieving an alternative product that gives extra value to the extracted coal.

\section{ACKNOWLEDGEMENTS}

The authors would like to thank the Group of Coals of the Faculty of Chemical Engineering of the Universidad del Valle, Cali, Colombia and Conicyt for the financing through the scholarship Postgraduate Thesis in the Industry Project 78111107

\section{REFERENCES}

1. S. Helle, G.H. Alfaro, U. Kelm, J.M.D. Tascon. Int. J. Coal. Geol. 44, 85, (2000).

2. C.A. Toles, W.E. MarshalL, M.M. Johns. Carbon 37, 1207, (1999).

3. P. Chingombe, B. Saha, R.J. Wakeman. Carbon 43, 3132, (2005).

4. N. Soudani, S. Najar-Souissi, A. Ouederni. J. Chil. Chem. Soc. 64, 4352, (2019).

5. L. Song-Woo, A. Wan Mohd, D. Wan, L. Min-Gyu. J. Ind. Eng. Chem. 16, 973, (2010).

6. P. Boraphech, P. Thiravetyan. J. Hazard. Mater. 284, 267, (2015).

7. C. Cháfer-Pericás, R. Herráez-Hernandez, P. Campins-Falto. J. Chromatogr. A. $81023,27,(2004)$

8. A.I. Mohammad, E.S. Jan, K. Ki-Hyun. Anal. Methods. 6, 5697, (2014)

9. H. Teng, H. Lin. AIChE. Journal. 44, 1170, (1998).

10. American Society for Testing Materials (ASTM) Committee. D. Standard Practice for Elemental Analysis of Coal and Coke, D5373 (2002).

11. American Society for Testing Materials (ASTM) Committee. D. Standard Practice for Proximate Analysis of Coal and Coke, D5142 (2005).

12. K. Baikia, R.K. Boruah, P.K. Gogoi. Bull. Mater. Sci. 30, 421, (2007).

13. B. Valentim, J.C. Jower, A. Guedes, D. Flores. IJECE. 147, (2011).

14. H.P. Boehm. Carbon. 40, 145, (2002).

15. ASTM D4607 - 94 Standard Test Method for Determination of Iodine Number of Activated Carbon, ASTM International, (2011).

16. A.F. Rojas-González, J.M. Barraza-Burgos. Ing. Univ. 17, 41, (2013). 